\title{
Why do some patients with Systemic Lupus Erythematosus fail to respond to B- cell depletion using Rituximab?
}

Sara Freitas, Internal Medicine department, Hospital Beatriz Angelo, Lisbon, Portugal, saracmfreitas@gmail.com

Marta Mozo Ruiz, Internal Medicine department, Hospital Universitario de Guadalajara, Guadalajara, Spain, martamozo.rz@gmail.com

Antonio Costa Carneiro, Internal Medicine department, Hospital de Cascais, Lisbon, Portugal, antoniolcarneiro@gmail.com

David Isenberg, Centre for Rheumatology, University College Hospital, London, United Kingdom, d.isenberg@ucl.ac.uk

\section{Corresponding author:}

David Isenberg

Address: Room 424, The Rayne Building, 5 University Street, London, WC1E 6JF, UK

E-mail: d.isenberg@ucl.ac.uk 


\section{ABSTRACT \\ Introduction}

The Centre for Rheumatology has treated 165 lupus patients with Rituximab since 2000. Our aim was to identify patients who failed to respond, identify any obvious distinguishing features, and to optimize individual patient treatment.

\section{Methods}

We reviewed all 165 lupus patients treated with Rituximab and reviewed the data up to 6 months after treatment. We excluded those who developed allergic reactions, had discoid lupus only or were lost follow-up. We assessed patients with active disease after 6 months, using the British Isles Lupus Assessment Group (BILAG) disease activity scores. Those patients whose A and B scores did not decrease, were deemed to have failed to respond.

\section{Results}

144 patients were included in the final analysis. The median disease duration was 6.68 (IQR 2.3211.90) years. $13.9 \%$ of the patients failed to decrease their BILAG scores. Two of the 144 patients died during the 6 months after treatment. The median BILAG at baseline was lower in the failure group (8.50, SD 6.00-12.75) at the time of treatment as opposed to those patients who improved $(17, \mathrm{SD} 12.0-23.0)(\mathrm{p}<0.001)$.

We found that patients with renal involvement failed less often than those without it $(\mathrm{p}=0.021)$. No other significant differences were observed.

\section{Conclusions}

Patients with a lower BILAG score are less likely to benefit from RTX treatment. Patients with renal involvement were less likely to fail to respond to RTX. We could not identify other features predictive of failure.

Key words: rituximab, B cell depletion therapy, failure, systemic erythematosus lupus

\section{Key messages:}

- Patients with lower BILAG scores tend to fail more to RTX treatment

- Patients with renal involvement fail less to RTX treatment

- $\quad$ RTX is an effective treatment in SLE patients 


\section{INTRODUCTION}

Systemic lupus erythematosus (SLE) is an autoimmune rheumatic disease characterized by an aberrant autoimmune response to self-antigens that can affect any organs or tissues and is associated with multiple clinical features.(1)

SLE treatment usually includes glucocorticoids (GC) and other immunosuppressive drugs according to the severity of the disease.(2) However, GC are associated with many side-effects and increased damage. Gladman et al. reported glucocorticoid related damage (measured by Systemic Lupus International Collaborating Clinics (SLICC)/American College of Rheumatology (ACR) Damage Index) in 49\% of cases at follow-up after 15 years. (3) Another study demonstrated that a prednisolone dose $>6 \mathrm{mg} /$ day was associated with higher risk of damage(4).Thus, other forms of treatment are necessary in order to reduce the GC burden.

B cell depletion treatment (BCDT) seems to be a valid option, since B cells have an important role in the pathogenesis of SLE through cytokine production, presentation of self-antigens, activation of T cells and antibody production. Rituximab (RTX) is a chimeric mouse/human monoclonal antibody against CD20 antigen on B cells and with low toxicity profile.(5)

Two major clinical trials of RTX, LUNAR(6) (patients with lupus nephritis) and EXPLORER(7) (patients with extra-renal SLE) failed to meet their end-points. However, concerns have been expressed about the patient selection, disease activity, end-point parameters and therapeutic protocols in those trials. Furthermore, there are many open-label studies that report a favourable clinical response with BCDT (reviewed in (8)) and RTX is now recommended in guidelines issued by European League Against Rheumatism (EULAR) (9) and ACR(10) for lupus nephritis and by the British Society for Rheumatology for more diverse SLE features(11). The potential capacity of BCD to reduce concomitant steroids has also been reported(12).

BCDT with RTX was introduced at University College Hospital (UCLH) in 2000. Since then the Centre for Rheumatology has treated 165 lupus patients, the vast majority of whom have failed a combination of steroids and two or more immunosuppressive drugs. In our prior publications, we have focused on the patients for whom this approach has been the most successful. Here we aim to identify patients who failed to respond and to address the question of whether there are any obvious distinguishing features, which will help the physician to personalise a patient's treatment.

\section{METHODS}


We reviewed all 165 patients diagnosed with lupus of the Centre for Rheumatology of UCLH treated with RTX until March 2018 and collected the data up to 6 months after the first RTX treatment.

We excluded patients who developed allergic reactions or had discoid lupus only (18 patients), two patients who have been treated on the onset of mild disease only (without A or B scores at baseline) and one patient that has been lost follow-up.

We have identified those patients who still had active disease after 6 months. This was defined by BILAG scores with new or persistent A or B scores.

The deceased patients during this period were also considered to be failures.

We recorded demographic characteristics; organ involvement; serological markers of disease activity such as anti-double-stranded DNA (dsDNA) antibody titters and serum complement (C3) levels; antinuclear antibodies (ANA); extractable nuclear antibodies (ENA)

(anti-Ro, anti-La, anti-Sm and anti-RNP antibodies) and circulating B lymphocytes (CD19+).

The previous treatment drugs were also recorded.

We used the classic BILAG assessments and letter scores were converted into numbers: $A=12$; $\mathrm{B}=5 ; \mathrm{C}=1 ; \mathrm{D} / \mathrm{E}=0(13)$.

BCD was considered to have been achieved when the absolute CD19 count decreased do $<0.005 \times 10^{9} / \mathrm{L}$ after treatment.

The analysis was performed using IBM SPSS Statistics version 20 for Mac OS X. $\chi^{2}$ test was used to compare proportions of qualitative variables. Student-t test was used to compare means of quantitative variables whenever the data meet the assumptions of the parametric test. Nonparametric test was used to compare quantitative variables in small samples that violate the assumption of normality.

The ethics committee at University College Hospital regards this type of study as an audit not requiring formal ethical approval.

\section{RESULTS}

\section{Demographic characteristics}

We reviewed the data on 144 patients with a mean age of 34.79 years (SD 12.45); 93.1\% female; 41.7\% Caucasian, $36.8 \%$ African-Caribbean and 6.3\% South-Asian. The median disease duration was 6.68 years (IQR 2.32-11.90).

As demonstrated on Table 1, there were no significant differences in terms of age, gender, ethnicity and duration of disease.

\section{Specific treatments}


Most of patients in this study (74.3\%) had failed a combination of steroids and two or more immunosuppressants. The great majority of patients $(98.6 \%)$ were being treated with prednisolone before beginning RTX treatment. There were no significant differences between the 2 groups in relation to previous medication with 4 or more drugs $(p=0.74)$.

\section{Disease activity measured by BILAG score}

Twenty patients (13.9\%) failed to decrease their BILAG score at 6 months. Most of the patients (73.6\%) decreased their score $\geq 5$ points and 67 patients (46.5\%) lost all their A and B scores without the development of new ones 6 months after RTX treatment. The mean decrease in global BILAG was 8.00 (IQR 4.00-16.25).

The median BILAG score at baseline was 15.00 (IQR 11.00-22.75). The median score was lower in the "failure group" (8.50, IQR 6.00-12.75) compared to patients in whom RTX was successful. In this later group higher scores were noted at the time of treatment (17.00, IQR 12.0-23.0) $(\mathrm{p}<0.001)$ (Table 2, Figure 1).

\section{Organ involvement}

At baseline, 74 patients (51.4\%) had musculoskeletal manifestations, haematological manifestations were observed in 62 patients (43.1\%), 60 patients $(41.7 \%)$ had mucocutaneous manifestations, 43 patients (29.9\%) had constitutional involvement, cardiorespiratory involvement was present in 24 patients (16.7\%), 16 patients (11.1\%) had neurological involvement and 8 patients (5.6\%) had vasculitis.

Renal involvement was present at baseline in 55 patients $(38.2 \%)$, three of whom $(2.08 \%)$ subsequently needed a renal transplant, five $(3.47 \%)$ were treated with dialysis and one patient $(0.69 \%)$ died because of renal failure. Renal biopsy was performed in 27 patients, and revealed nephritis class II in one patient, nephritis class III in four patients, nephritis class IV in 15 patients and class $\mathrm{V}$ in seven patients. Only one patient with renal involvement failed to respond to RTX (nephritis class 5, without renal failure).

Twenty-six patients (18.1\%) had 4 or more organs/systems involved and only two did not respond to RTX treatment.

Antiphospholipid syndrome was observed in 15 patients (10.4\%), two of whom failed to respond to RTX.

Patients with renal involvement failed less often (5.5\%) than those without it (19.1\%) (OR 0.244; IC95\% 0.068-0.877; $\mathrm{p}=0.021$ ).

No other significant differences in specific organ/systems, or the numbers of organs/systems involved were observed between the groups.

\section{Serological markers}

The great majority of patients $(96.5 \%)$ had positive ANA at the time of the first RTX infusion. Anti-Ro antibody was present in 74 patients (51.4\%), anti-La antibody was positive in 32 patients 
(22.2\%), anti-Sm antibody was present in 45 patients (31.3\%) and 66 patients (45.8\%) had a positive anti-RNP antibody.

Anti-cardiolipin antibody (IgG or $\operatorname{IgM}$ ) was positive in 26 patients (18.1\%), anti-beta2glycoprotein antibody (IgG or $\operatorname{IgM})$ was positive in 8 patients (5.6\%) and 16 patients $(11.1 \%)$ had positive lupus anticoagulant.

Anti-dsDNA antibody was high at baseline in 92 patients (63.9\%) and 93 patients (64.6\%) had low C3 levels.

In the group of patients [ $\mathrm{n}=$ ?] with renal failure, there was a significant difference between patients with high anti-ds-DNA antibody $(\mathrm{p}=0.028)$ but no significant difference concerning low C3 levels $(\mathrm{p}=0.234)$. No other significant differences between the groups were seen regarding the presence of specific autoantibodies or low $\mathrm{C} 3$ values.

$\mathrm{BCD}$ (measured by $\mathrm{CD}^{+} 19$ levels after treatment) was achieved in all patients except 8 (5.6\%), although, interestingly, only one of these failed to show some benefit. There are no significant differences between the groups that showed clinical benefit and the "failure group".

\section{Mortality}

Of the 144 patients two died during the 6-month post RTX period. One patient unfortunately died after an RTX infusion and concomitant cyclophosphamide to an acute respiratory distress syndrome (thought to be a reaction to cyclophosphamide) and another due do infective endocarditis with mitral valve disorder.

\section{DISCUSSION}

A minority of our SLE patients (13.9\%) treated with RTX failed to respond to BCDT with RTX at 6 months and, as mentioned above, there were no differences in $\mathrm{BCD}$ response between the 2 groups.

Although there is an established correlation between $\mathrm{BCD}$ and clinical response, some patients who achieve BCD [REF NEEDED], still do not achieve a favourable clinical response after treatment. Lazarus et al. [REF missing] demonstrated that some patients with low B cell levels relapsed with high anti-dsDNA antibody levels while other patients relapsed with B cell levels similar to those prior to BCDT and low anti-dsDNA antibody levels. Thus, the pathogenesis of SLE in those patients may simply be less dependent upon direct B cell abnormalities and/or due protection mechanisms against RTX cytotoxicity. Thus RTX would be less likely to be effective for them at least in terms of monotherapy.

As we have described previously (14), patients treated with BCDT in which BCD was achieved, had favourable clinical response which was associated with a decrease in anti-dsDNA antibody levels but without a change in anti-ENA status or antimicrobial antibody levels. This could be due to difficult vascular access to some antibody producing B cell clones, or local pro-survival 
signs or because anti-dsDNA antibodies are mainly produced by short-lived plasma cells as opposed to fully differentiated B cells that do not express CD20 and possible produce anti-ENA antibodies and are therefore less responsive to RTX treatment(15).

Another factor that seems to have an important role in SLE pathogenesis is the B lymphocyte stimulator (BLyS). Carter et al. demonstrated an inverse relation between BLyS levels and B cell count after RTX treatment, with peak levels correlating with the nadir of B cells and a positive correlation between BLyS and anti-dsDNA antibodies levels during relapse. They also demonstrated that flares at the lowest B cells counts were associated with the highest BLyS levels (16). Hence, elevated BLyS levels seem to have a role in SLE relapsing after BCDT and BLyS blockade treatment may have an important role in association with RTX.

Patients that failed to respond to BCDT had lower BILAG scores at baseline compared to patients who did not fail to this treatment. Arguably, the presence of higher disease activity, and therefore higher BILAG scores, provides a greater possibility to demonstrate clinical improvement as compared to these patients with less active disease.

Although the main aim of this study was to understand why some patients fail to respond to RTX treatment, we also conclude that patients with renal involvement tend to fail RTX treatment less often. Those patients also had higher disease activity with high anti-dsDNA antibody levels.

This study has some limitations. It is retrospective and the full previous drug dosage and exact duration of previous treatments were difficult to collect comprehensively. It would be also interesting to evaluate BLyS levels in further studies in patients treated with RTX who fail to respond.

The purpose of this study was to evaluate whereas there were specific characteristics that could predispose to RTX failure in patients with SLE but we could not identify them, except for lower BILAG score at baseline in those patients (which could simply reflect a less effective response in patients with less active disease). 


\section{REFERENCES}

1. La Paglia G, Leone M, Lepri G, Vagelli R, Valentini E, Alunno A, et al. One year in review 2017: systemic lupus erythematosus. Clin Exp Rheumatol 2017;551-61.

2. Gracia-Tello B, Ezeonyeji A, Isenberg DA. The use of rituximab in newly diagnosed patients with systemic lupus erythematosus: Long-term steroid saving capacity and clinical effectiveness. Lupus Sci Med 2017 published on 2 february of 2017. doi:10.1136/lupus-2016-000182

3. Gladman D, Urowitz M, Rahman P, Ibañez D, Tam L. Accrual of organ damage over time in patients with systemic lupus erythematosus. J Rheumatol 2003;30:1955-9.

4. Thamer M, Hernán M, Zhang Y, Cotter D, Petri M. Prednisone, lupus activity, and permanent organ damage. J Rheumatol 2009;36:560-4.

5. Cunha JS, Gilek-Seibert K. Systemic Lupus Erythematosus: A Review of the Clinical Approach to Diagnosis and Update on Current Targeted Therapies. R I Med J 2013;99:237.

6. Rovin BH, Furie R, Latinis K, Looney RJ, Fervenza FC, Sanchez-Guerrero J, et al. Efficacy and safety of rituximab in patients with active proliferative lupus nephritis: the Lupus Nephritis Assessment with Rituximab study. Arthritis Rheum 2012;64:1215-26.

7. Merrill JT, Neuwelt CM, Wallace DJ, Shanahan JC, Latinis KM, Oates JC, et al. Efficacy and safety of rituximab in moderately-to-severely active systemic lupus erythematosus: The randomized, double-blind, phase II/III systemic lupus erythematosus evaluation of rituximab trial. Arthritis Rheum 2010;62:222-33.

8. Ramos L, Isenberg DA. Rituximab: the Lupus Journey. Curr Treat Options Rheumatol 2015;1:30-41. 
9. Bertsias GK, Tektonidou M, Amoura Z, Aringer M, Bajema I, Berden JHM, et al. Joint European League Against Rheumatism and European Renal Association-European Dialysis and Transplant Association (EULAR/ERA-EDTA) recommendations for the management of adult and paediatric lupus nephritis. Ann Rheum Dis 2012;71:1771-82.

10. Hahn BH, McMahon MA, Wilkinson A, Wallace WD, Daikh DI, Fitzgerald JD, et al. American College of Rheumatology guidelines for screening, treatment, and management of lupus nephritis. Arthritis Care Res 2012;64:797-808.

11. Gordon C, Amissah-Arthur MB, Gayed M, Brown S, Bruce IN, D’Cruz D, et al. Comment on: The British Society for Rheumatology guideline for the management of systemic lupus erythematosus in adults: reply. Rheumatology 2018;57:1502-3.

12. Condon MB, Ashby D, Pepper RJ, Cook HT, Levy JB, Griffith M, et al. Prospective observational single-centre cohort study to evaluate the effectiveness of treating lupus nephritis with rituximab and mycophenolate mofetil but no oral steroids. Ann Rheum Dis 2013;72:1280-6.

13. Cresswell L, Yee C-S, Farewell V, Rahman A, Teh L-S, Griffiths B, et al. Numerical scoring for the Classic BILAG index. Rheumatology 2009;48:1548-52.

14. Cambridge G, Leandro MJ, Teodorescu M, Manson J, Rahman A, Isenberg DA, et al. B cell depletion therapy in systemic lupus erythematosus: Effect on autoantibody and antimicrobial antibody profiles. Arthritis Rheum 2006;54:3612-22.

15. Cambridge G, Isenberg DA, Edwards JC, Leandro MJ, Migone TS, Teodorescu M, et al. B cell depletion therapy in systemic lupus erythaematosus: Relationships among serum B lymphocyte stimulator levels, autoantibody profile and clinical response. Ann Rheum Dis 2008;67:1011-6.

16. Carter LM, Isenberg DA, Ehrenstein MR. Elevated serum BAFF levels are associated with rising anti-double-stranded DNA antibody levels and disease flare following B cell depletion therapy in systemic lupus erythematosus. Arthritis Rheum 2013;65:2672-9. 
Table 1_ Comparison between patients who failed and did not fail to Rituximab treatment in terms of demographic features and disease duration.

\begin{tabular}{|c|c|c|c|c|}
\hline Characteristics & $\begin{array}{c}\text { Total } \\
\mathrm{N}=144\end{array}$ & $\begin{array}{l}\text { Failure to } \text { RTX }^{a} \\
\mathrm{~N}=20(13.9 \%)\end{array}$ & $\begin{array}{c}\begin{array}{c}\text { Non-failure to } \\
\text { RTX }\end{array} \\
\mathrm{N}=124(85.5 \%)\end{array}$ & p-value ${ }^{b}$ \\
\hline Age, mean (SD) years & $34.79(12.45)$ & 33.30 & 35.03 & $0.566 * *$ \\
\hline \multicolumn{5}{|l|}{ Gender } \\
\hline Female, $\mathrm{N}$ & 134 & 20 & 114 & $0.358 *$ \\
\hline Male, $\mathrm{N}$ & 10 & 0 & 10 & \\
\hline \multicolumn{5}{|l|}{ Ethnicity } \\
\hline Caucasian, $\mathrm{N}$ & $60(41.7 \%)$ & 11 & 49 & $0.184^{*}$ \\
\hline African-Caribbean, $\mathrm{N}$ & $53(36.8 \%)$ & 3 & 50 & \\
\hline South Asian, N & $18(12.5 \%)$ & 4 & 14 & \\
\hline North Asian, N & $9(6.3 \%)$ & 2 & 7 & \\
\hline Other, $\mathrm{N}$ & $4(2.8 \%)$ & 0 & 4 & \\
\hline $\begin{array}{l}\text { Disease duration, median (IQR) } \\
\text { years }\end{array}$ & $6.68(2.32-11.90)$ & $8.43(3.12-11.73)$ & $6.55(2.06-11.96)$ & $0.534 * * *$ \\
\hline
\end{tabular}

IQR: interquartile range; RTX: rituximab; SD: standard deviation.

${ }^{a}$ We consider failure to Rituximab in patients who still had active disease after 6 months, defined by BILAG scores with an A and/or B that had increased or maintained their scores.

${ }^{\mathrm{b}}$ Comparison between the characteristics of the patients who fail to respond to Rituximab and those who respond to it: 
$* \chi^{2}$ test was used to compare proportions of qualitative variables

** Student-t test was used to compare means of quantitative variables whenever the data meet the assumptions of the parametric test

*** Non-parametric test was used to compare quantitative variables in small samples that violate the assumption of normality

Table 2_ Comparison between patients who failed and did not fail to Rituximab treatment in terms of clinical and serological features.

\begin{tabular}{|c|c|c|c|c|}
\hline Characteristics & $\begin{array}{c}\text { Total } \\
\mathrm{N}=144\end{array}$ & $\begin{array}{l}\text { Failure to } \mathrm{RTX}^{\mathrm{a}} \\
\mathrm{N}=20(13.9 \%)\end{array}$ & $\begin{array}{c}\text { Non-failure to } \\
\text { RTX } \\
\mathrm{N}=124(85.5 \%)\end{array}$ & $p$-value ${ }^{b}$ \\
\hline $\begin{array}{l}\text { BILAG score at baseline, median } \\
\text { (IQR) }\end{array}$ & $\begin{array}{l}15.00(11.00- \\
22.75)\end{array}$ & $8.50(6.00-12.75)$ & $\begin{array}{l}17.00(12.00- \\
23.00)\end{array}$ & $<0.001 * * *$ \\
\hline $\begin{array}{l}\text { BILAG score } 6 \text { months after } \\
\text { RTX, median (IQR) }\end{array}$ & $5.50(2.00-8.00)$ & $\begin{array}{c}11.50(7.00- \\
13.75)\end{array}$ & $5.00(2.00-8.00)$ & $<0.001 * * *$ \\
\hline $\begin{array}{l}\text { Serological disease activity } \\
\text { markers } \\
\text { High dsDNA, N (\%) } \\
\text { Low C3, N (\%) }\end{array}$ & $93(64.6 \%)$ & 15 & 78 & $0.286^{*}$ \\
\hline
\end{tabular}




\begin{tabular}{|c|c|c|c|c|}
\hline \multicolumn{5}{|l|}{ Organ Involvement } \\
\hline Constitutional symptoms, $\mathrm{N}$ & $43(29.9 \%)$ & 5 & 38 & $0.609 *$ \\
\hline Mucocutaneous involvement, $\mathrm{N}$ & $60(41.7 \%)$ & 9 & 51 & $0.745 *$ \\
\hline Neurological involvement, $\mathrm{N}$ & $16(11.1 \%)$ & 4 & 12 & $0.240 *$ \\
\hline Musculoskeletal involvement, $\mathrm{N}$ & $74(51.4 \%)$ & 7 & 67 & $0.114 *$ \\
\hline Cardiorespiratory involvement, $\mathrm{N}$ & $24(16.7 \%)$ & 3 & 21 & $1.000 *$ \\
\hline Vasculitis, $\mathrm{N}$ & $8(5.6 \%)$ & 0 & 8 & $0.600 *$ \\
\hline Renal involvement, $\mathrm{N}$ & $55(38.2 \%)$ & 3 & 52 & $0.021 *$ \\
\hline Haematological involvement, $\mathrm{N}$ & $62(43.1 \%)$ & 10 & 52 & $0.499 *$ \\
\hline $\begin{array}{l}\text { Number of organs and systems } \\
\text { involved, median (IQR) }\end{array}$ & $2.00(1.00-3.00)$ & $1.50(1.00-3.00)$ & $2.00(1.25-3.00)$ & $0.103 * * *$ \\
\hline
\end{tabular}

IQR: interquartile range; RTX: rituximab; SD: standard deviation.

${ }^{a}$ We consider failure to Rituximab in patients who still had active disease after 6 months, defined by BILAG scores with an A and/or B that had increased or maintained their scores.

${ }^{\mathrm{b}}$ Comparison between the characteristics of the patients who fail to respond to Rituximab and those who respond to it:

* $\chi^{2}$ test was used to compare proportions of qualitative variables

** Student-t test was used to compare means of quantitative variables whenever the data meet the assumptions of the parametric test

*** Non-parametric test was used to compare quantitative variables in small samples that violate the assumption of normality
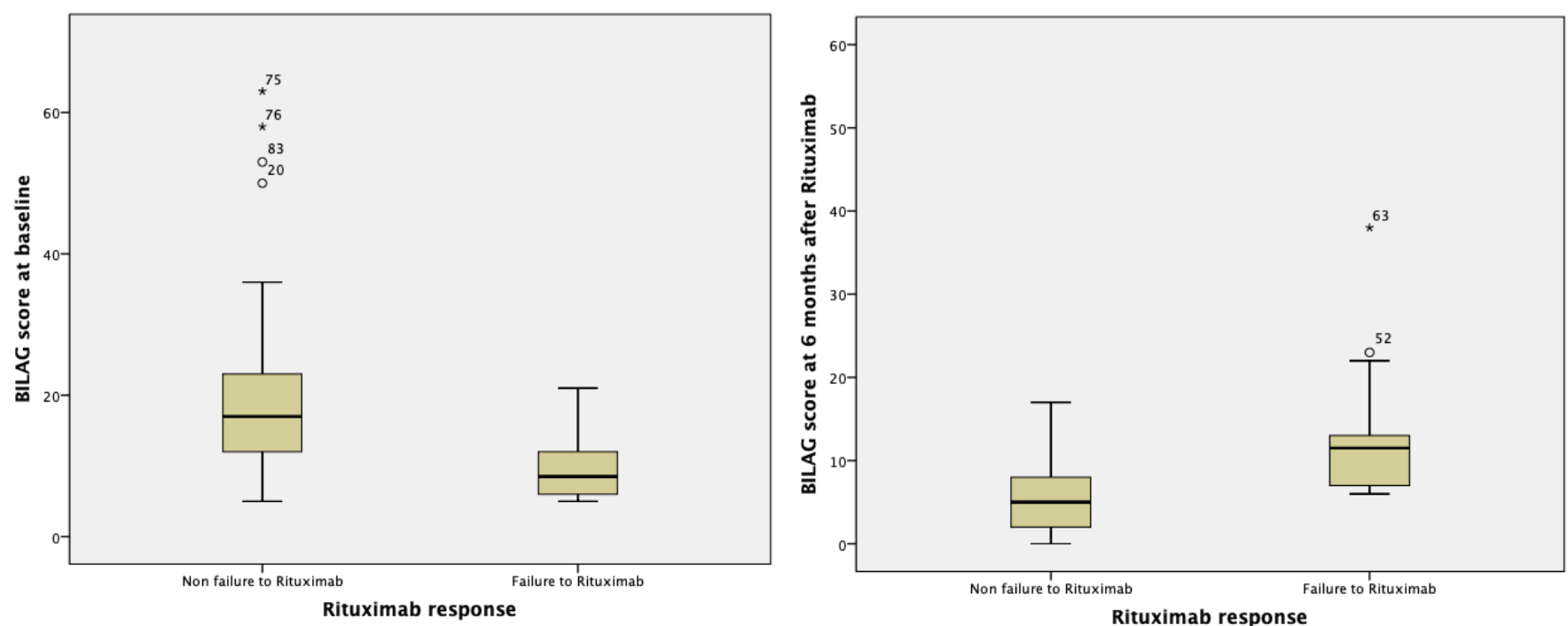

Figure 1_ BILAG score comparison between patients that failed and did not fail to respond to Rituximab at baseline and 6 months after rituximab treatment. 
